\title{
Erratum to: Intra-articular Injection of Urinary Bladder Matrix Reduces Osteoarthritis Development
}

\author{
Heather N. Jacobs, ${ }^{1}$ Sona Rathod, ${ }^{1}$ Matthew T. Wolf, ${ }^{1}$ and Jennifer H. Elisseeff ${ }^{1,2,3}$
}

Published online 14 November 2016

\section{Erratum to: AAPS J}

DOI: 10.1208/s12248-016-9999-6

The original article had one of the authors incorrectly listed as "Matthew Wolf" instead of "Matthew T. Wolf". The original article was corrected.

The online version of the original article can be found at http:// dx.doi.org/10.1208/s12248-016-9999-6.

\footnotetext{
${ }^{1}$ Translational Tissue Engineering Center, Wilmer Eye Institute and Department of Biomedical Engineering, Johns Hopkins University, Baltimore, Maryland 21287, USA.

2 400N Broadway, Baltimore, Maryland 21232, USA.

${ }^{3}$ To whom correspondence should be addressed. (e-mail: jhe@jhu.edu)
} 